\title{
Factors Associated with Condom Knowledge, Attitude, and Use among Black Heterosexual Men in Ontario, Canada
}

\author{
Josephine Etowa $\mathbb{D}^{1},{ }^{1}$ Bishwajit Ghose $\mathbb{D}^{1},{ }^{1}$ Hughes Loemba, ${ }^{2}$ Egbe B. Etowa, \\ Winston Husbands, ${ }^{3}$ Francisca Omorodion, ${ }^{4}$ Isaac Luginaah, ${ }^{5}$ \\ and Josephine Pui-Hing Wong ${ }^{6}$ \\ ${ }^{1}$ Faculty of Health Sciences, School of Nursing, University of Ottawa, Ottawa, Ontario, Canada \\ ${ }^{2}$ Montfort Hospital, Ottawa, Ontario, Canada \\ ${ }^{3}$ Ontario HIV Treatment Network, 1300 Yonge Street, Suite 600, Toronto, ON M4T 1X3, Canada \\ ${ }^{4}$ Department of Sociology, Anthropology \& Criminology, University of Windsor, Windsor, Canada \\ ${ }^{5}$ Department of Geography, Western University, London, Ontario, Canada \\ ${ }^{6}$ Daphne Cockwell School of Nursing, Faculty of Community Services, Ryerson University, Toronto, Ontario, Canada
}

Correspondence should be addressed to Josephine Etowa; josephine.etowa@uottawa.ca

Received 29 August 2020; Revised 3 April 2021; Accepted 21 April 2021; Published 3 May 2021

Academic Editor: Gianandrea Pasquinelli

Copyright (c) 2021 Josephine Etowa et al. This is an open access article distributed under the Creative Commons Attribution License, which permits unrestricted use, distribution, and reproduction in any medium, provided the original work is properly cited.

\begin{abstract}
African, Caribbean, and Black (ACB) men living in Canada share a heightened risk of HIV infection and the associated risk factors such as suboptimal use of family planning services such as condom use. In this study, we assessed the factors associated with knowledge, attitude, and condom use among ACB men in Ontario. Methods. This was a cross-sectional study that surveyed heterosexual ACB men regardless of their residency status living in Ontario $(n=430)$. This is a part of a larger mixed methods study informed by critical race theory, intersectionality, and community-based participatory research (CBPR). Outcome variables were knowledge of condom use, attitude towards condom use, and actual use of condom during the last 12 months. Results. Of 430 participants, $77.70 \%$ has good knowledge of condom use as a protection against HIV transmission, $31.77 \%$ had positive attitude towards condom use, and $62.43 \%$ reported using condom regularly with casual partners during the last 12 months. Men who were currently married had more positive attitude towards condom use compared with their unmarried counterparts (odds ratio $=1.46$, $95 \% \mathrm{CI}=1.20,1.78$ ). Canadian residents were found to have higher odds of having correct knowledge of condom (odds ratio $=1.31,95 \% \mathrm{CI}=1.11,1.55$ ), and positive attitude towards condom use (odds ratio $=1.44,95 \% \mathrm{CI}=1.09,1.92$ ). Men who visited sexual health clinics showed a positive association with having correct knowledge of condom (odds ratio $=1.78,95 \%$ $\mathrm{CI}=1.30,2.44)$ and reported experiences of difficulty in accessing sexual health. This showed a negative association towards condom use (odds ratio $=0.45,95 \% \mathrm{CI}=0.21,0.97$ ]. Conclusion. A considerable percentage of heterosexual ACB men did not have correct knowledge regarding the protective effect of condom use against HIV and positive attitude towards the use of condom. Several sociodemographic and healthcare-related factors were significantly associated with knowledge, attitude, and use of condom.
\end{abstract}

\section{Introduction}

Globally, condom use is an important method of family planning and prevention of sexually transmitted infections, especially HIV/AIDS in order to improve health and quality of life [2]. Universal provision and utilization of family planning (FP) services is regarded as one of the key strategies to achieving several sustainable development goals (SDGs), especially those relevant to prevention of life-threatening diseases such as HIV/AIDS [3-5]. A great majority of the population are aware of some form of modern contraceptive methods and have reported willingness to adopt a method of 
birth control and family planning [6, 7]; nonetheless, unmet need for and nonuse of FP are still widely prevalent and is leading to high rates of HIV infections among marginalised population such as the African, Caribbean, and black communities [4, 8-11]. Studies have shown that when used consistently and correctly, condoms are highly effective in preventing the transmission of a range of sexually transmitted infections (STIs) including HIV, gonorrhoea, chlamydia, trichomoniasis, hepatitis B, genital herpes, syphilis, chancroid, and human papillomavirus infection [12-14]. The situation is particularly challenging for ACB men who account for a disproportionately higher percentage of people living with HIV [15]. The lower prevalence of condom among men is generally attributable to a certain extent to their contraceptive preferences and perception of health risks, and the limiting effect of various sociocultural determinants such as poor health literacy, misconception, careseeking behaviour, and nonuse of the available services is also well documented [16-19].

The number of ACB immigrants has been increasing constantly in Canada and represents one of the fastest growing ethnic subpopulations in the country. The major driving forces behind this influx are generally the need for safety, better livelihood and income opportunities, better health and living condition, and family reunification [20]. Canada's healthcare system boasts one of the most advanced in the world especially for providing an immigrant-friendly labour market and healthcare landscape. However, a host of challenges continue to persist in providing care in an equitable manner among immigrants from low- and middleincome countries who are more likely to have different health issues and needs compared with the local population [21]. The inherent difficulties in providing care for this disadvantaged population group, coupled with their exposure to risk factors (such as low income and health literacy), can significantly increase their vulnerability to STIs and receiving the health service in a timely manner. Several studies have highlighted this complexity linked to immigrants' sociocultural backgrounds, social capital, educational, employment, and living conditions and legal statuses with their vulnerability for HIV transmission and other sexual health issues $[20,22,23]$.

Given this, there is a critical need for expanding the provision and use of condom among ACB men. Unfortunately, lack of quality data and structural gaps in healthcare systems met with financial, socioeconomical, and technological obstacles among ACB men remain a major barrier to solve the situation [24]. To this regard, we undertook the present study with the aim of investigating the factors associated with condom use among ACB men. The data came from the weSpeak project; this represents a five-year multisite (Ottawa, Toronto, London, and Windsor) research programme that aims to (1) assess the sociocultural and sociopolitical conditions that contribute to HIV-related health disparities among ACB men, (2) examine social and behavioural vulnerabilities to HIV among ACB men, including their social identities related to race, class, gender, and sexualities; and (3) generate, appraise, and share new knowledge and support its translation into intervention and practice. weSpeak is a mixed methods study comprising focus groups, in-depth interviews, and a questionnaire survey. The present analysis was based on quantitative data only $[25,26]$.

\section{Methods}

2.1. Sampling and Recruitment. We estimated the survey sample size for each city based on the number of HIV tests performed among heterosexual ACB men over 5 years, 2007-2011, in relation to the total male ACB population aged 15 years and older in the respective cities from the 2011 National Household Survey, with an additional desired level of precision of 5\%. For example, 15,465 tests were attributed to ACB men in Toronto, which represents $12 \%$ of Toronto's black male population aged 15 and older in 2011. We doubled the initial estimated sample size for Toronto. Moreover, based on the experience with the MaBwana study, [27] we increased the sample size in all four cities by $25 \%$ to achieve greater statistical power and also made allowances for questionnaires/cases that were incomplete or ineligible. Our sample estimates were as follows-Toronto: revised sample size estimate $(n=324)$, recruitment target $(n=405)$; Ottawa: initial sample size estimate $(n=207)$, recruitment target $(n=259)$; London: initial sample size estimate $(n=160)$, recruitment target $(n=200)$; and Windsor: initial sample size estimate $(n=140)$, recruitment target $(n=175)$. Based on the targets above, our sample for the survey was close to 1,039 self-identified heterosexual ACB men, which, in the context of research with ACB communities in Canada, constitutes a large sample. The experiences and perspectives of men living with HIV are germane to the study, but ACB men infected with HIV through heterosexual contact represent less than $2 \%$ of the adult male ACB population in various cities in Ontario. To support analysis of data on HIV-positive heterosexual men, we recruited at least $167 \mathrm{HIV}$-positive men (i.e., 167/831 or $20 \%)$ consisting of 65 in Toronto, 42 in Ottawa, 32 in London, and 28 in Windsor. This study was limited to participants who mentioned having any sexual partner during the last 12 months.

Variables: The outcome variables were knowledge of condom use, attitude towards condom use, and use of condom during the last 12 months. Knowledge was assessed by the question: are condoms the best way to protect myself against HIV transmission? The answers were coded as good (if replied yes) and not good (if replied no/don't know). Attitude was assessed as a composite score to a set of questions regarding the use of condom: is it uncomfortable, is it not appealing, does it make sex unenjoyable, does it enhance sexual pleasure, would avoid if possible, does it mean a sign of concern and responsibility, is it unmanly, and just don't like the idea? Answers for all these items ranged from strongly agree to strongly disagree. Based on the context, some of the answers were reverse recoded to calculate a global score, which was finally divided into quantiles. Those whose answers were in the fourth and fifth quantile were recoded as having positive attitude, and the rest were 
TABle 1: Descriptive analysis of condom knowledge, attitude, and utilization among ACB men in Ontario.

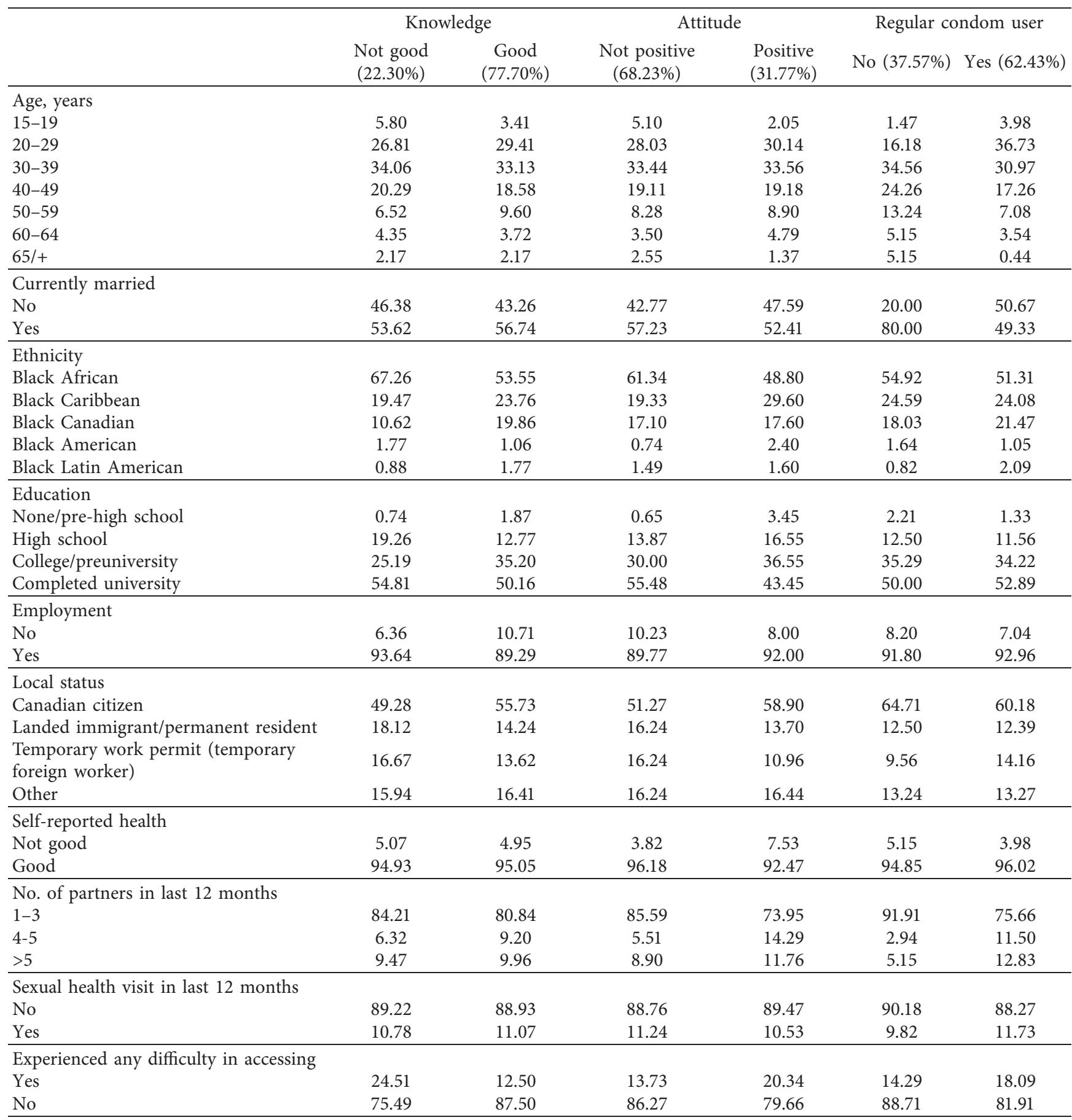

recoded as "negative attitude." Condom use during the last 12 months with casual partners was coded as "user" and "nonuser."

Explanatory variables: Literature review was conducted in PUBMED for articles published on similar topics to identify a list of sociodemographic variables that are associated with condom knowledge, attitude, and practice. Based on the results of the review, the following variables were included in the analysis: age (15-19/20-29/30-39 40-49/ 50-59/60-64/65/+); currently married (No/Yes); ethnicity
(Black African/Black Caribbean/Black Canadian/Black American/Black Latin American); education (None/ Pre-High School/High School/College/Preuniversity/Completed University); employment (No/Yes); local status (Canadian Citizen/Landed Immigrant \& Permanent Resident/Temporary Work Permit/Other); self-reported health (Not Good/Good); no. of partners in last 12 months (1-3/ $4-5 />5$ ); sexual health visit in last 12 months (No/Yes); and experienced any difficulty in accessing sexual healthcare (Yes/No). 


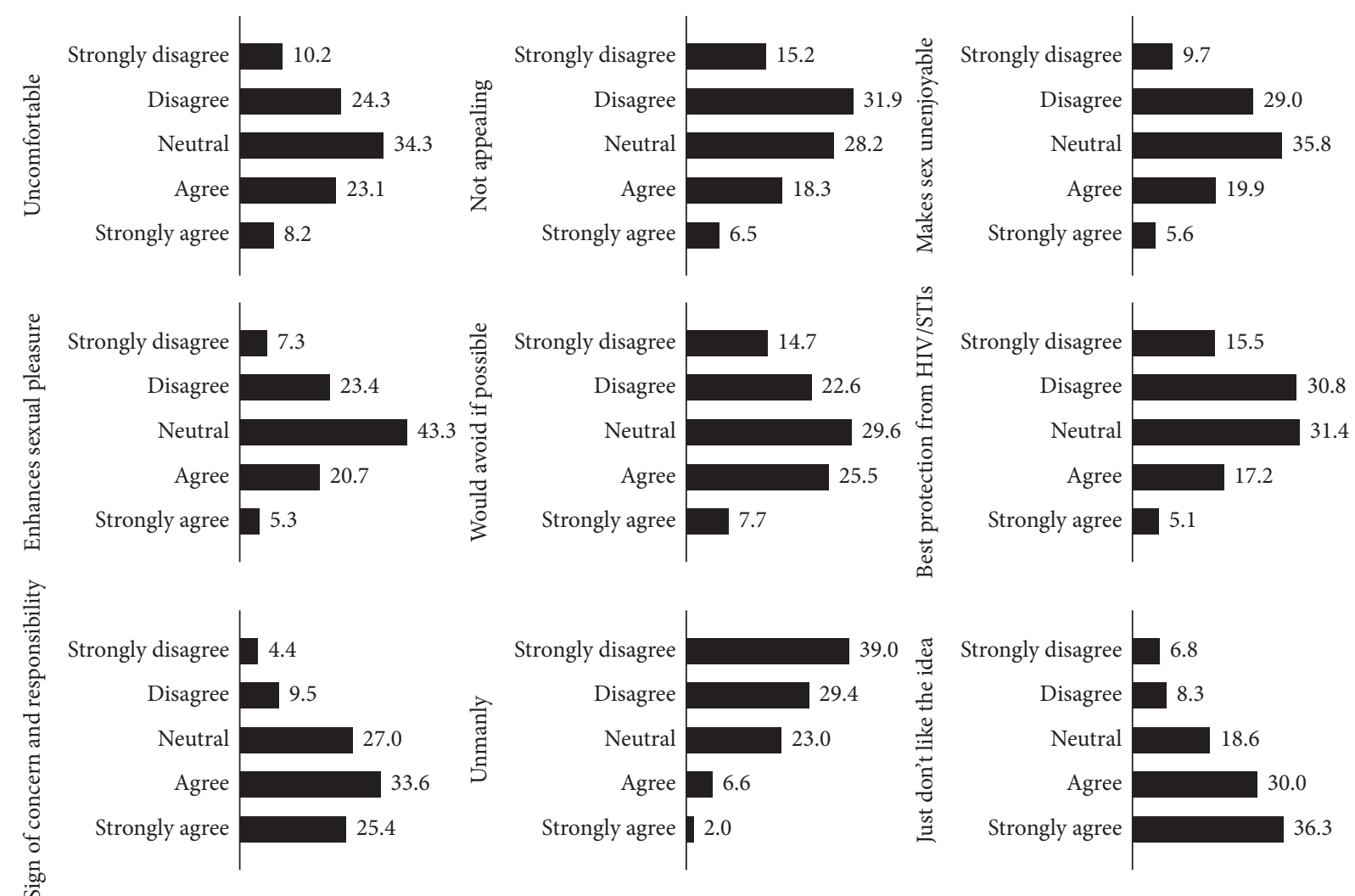

Figure 1: Responses on condom knowledge and attitude.

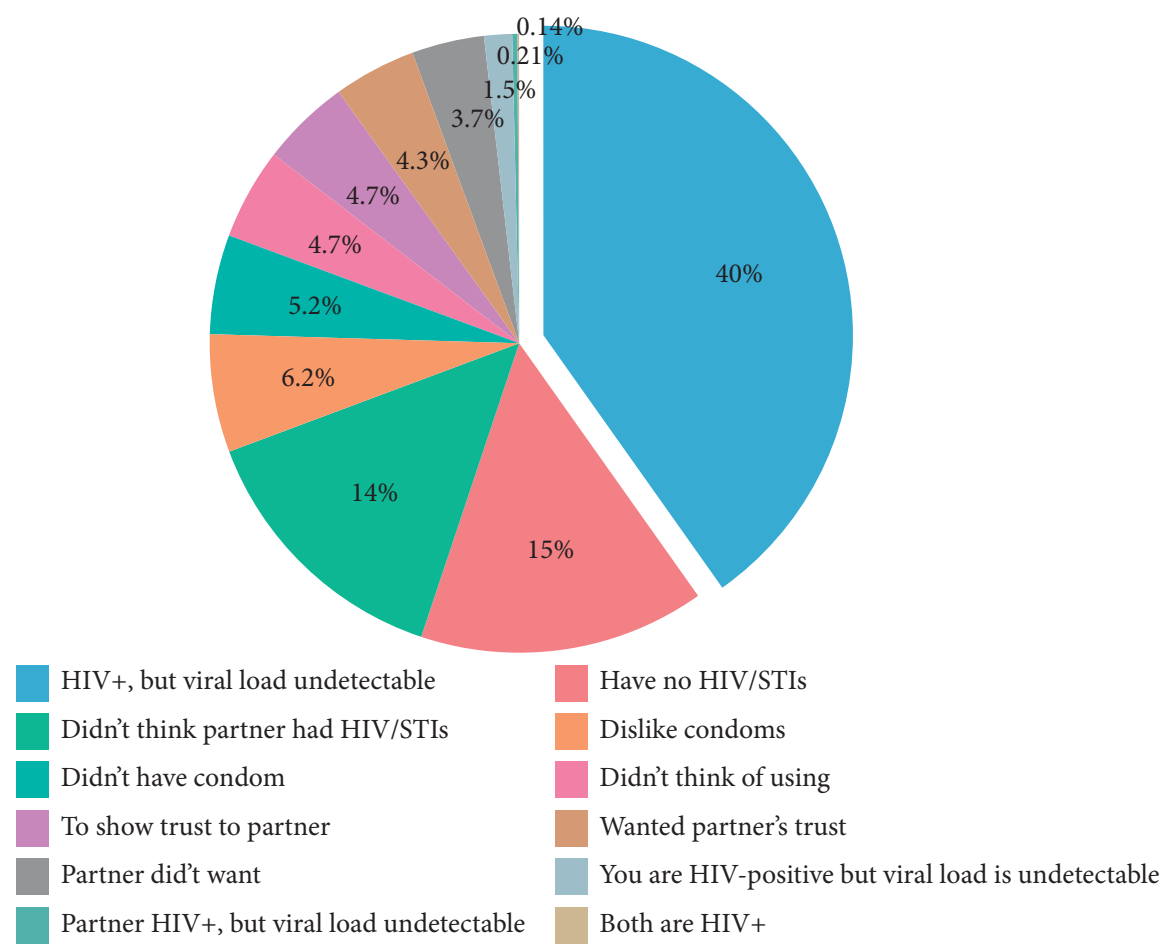

FIGURE 2: Reasons for not using condoms with the last partner.

2.2. Statistical Analysis. Data were cross-checked by two independent researchers before entering into Stata for analysis. Some of the variables were recoded into smaller categories for the purpose of the regression analysis. Data were analysed by using Stata, version 14, and R. Descriptive analyses were performed to present the basic sociodemographic 
TABLE 2: Factors associated with condom knowledge, attitude, and use among ACB men in Ontario.

\begin{tabular}{|c|c|c|c|}
\hline & Knowledge & Attitude & Condom use \\
\hline \multicolumn{4}{|l|}{ Age groups $(65 /+)$} \\
\hline $15-19$ years & $\begin{array}{c}1.25^{*} \\
{[1.02,1.53]}\end{array}$ & $\begin{array}{c}2.03^{* *} \\
{[1.24,3.34]}\end{array}$ & $\begin{array}{c}1.38 \\
{[0.95,2.02]}\end{array}$ \\
\hline 20-29 years & $\begin{array}{c}1.15 \\
{[0.91,1.44]}\end{array}$ & $\begin{array}{c}0.89 \\
{[0.54,1.46]}\end{array}$ & $\begin{array}{c}1.58^{*} \\
{[1.01,2.48]}\end{array}$ \\
\hline 30-39 years & $\begin{array}{c}1.78^{* * *} \\
{[1.41,2.24]}\end{array}$ & $\begin{array}{c}1.74^{*} \\
{[1.12,2.70]}\end{array}$ & $\begin{array}{c}2.00^{* *} \\
{[1.21,3.31]}\end{array}$ \\
\hline $40-49$ years & $\begin{array}{c}2.68^{* * *} \\
{[2.12,3.37]}\end{array}$ & $\begin{array}{l}2.95^{* * *} \\
{[1.88,4.64]}\end{array}$ & $\begin{array}{l}2.77^{* * *} \\
{[1.67,4.60]}\end{array}$ \\
\hline $50-59$ years & $\begin{array}{c}1.38 \\
{[0.63,3.00]}\end{array}$ & $\begin{array}{c}1.24 \\
{[0.42,3.67]}\end{array}$ & $\begin{array}{c}0.12 \\
{[0.01,1.62]}\end{array}$ \\
\hline $60-64$ years & $\begin{array}{c}1.20 \\
{[0.56,2.58]}\end{array}$ & $\begin{array}{c}0.91 \\
{[0.32,2.61]}\end{array}$ & $\begin{array}{c}0.09 \\
{[0.01,1.19]}\end{array}$ \\
\hline \multicolumn{4}{|l|}{ Currently married (no) } \\
\hline Yes & $\begin{array}{c}0.99 \\
{[0.82,1.19]}\end{array}$ & $\begin{array}{c}1.46^{* * *} \\
{[1.20,1.78]}\end{array}$ & $\begin{array}{c}1.14 \\
{[0.75,1.74]}\end{array}$ \\
\hline \multicolumn{4}{|l|}{ Ethnicity (Black African) } \\
\hline Black Caribbean & $\begin{array}{c}1.45 \\
{[0.68,3.09]}\end{array}$ & $\begin{array}{c}1.30 \\
{[0.46,3.71]}\end{array}$ & $\begin{array}{c}0.22 \\
{[0.02,2.94]}\end{array}$ \\
\hline Black Canadian & $\begin{array}{c}1.31 \\
{[0.62,2.81]}\end{array}$ & $\begin{array}{c}1.60 \\
{[0.57,4.54]}\end{array}$ & $\begin{array}{c}0.09 \\
{[0.01,1.19]}\end{array}$ \\
\hline Black Latin American & $\begin{array}{c}1.23 \\
{[0.57,2.64]}\end{array}$ & $\begin{array}{c}1.05 \\
{[0.36,3.04]}\end{array}$ & $\begin{array}{c}0.14 \\
{[0.01,1.86]}\end{array}$ \\
\hline \multicolumn{4}{|l|}{ Education (completed university) } \\
\hline College/Preuniversity & $\begin{array}{c}0.77 \\
{[0.47,1.26]}\end{array}$ & $\begin{array}{c}0.60 \\
{[0.27,1.31]}\end{array}$ & $\begin{array}{c}0.30^{*} \\
{[0.10,0.94]}\end{array}$ \\
\hline High school & $\begin{array}{c}0.85^{*} \\
{[0.74,0.98]}\end{array}$ & $\begin{array}{c}0.86 \\
{[0.68,1.10]}\end{array}$ & $\begin{array}{c}0.89 \\
{[0.66,1.21]}\end{array}$ \\
\hline None/pre-high school & {$[0.92,1.49]$} & $\begin{array}{c}1.09 \\
{[0.72,1.65]}\end{array}$ & {$[0.44,1.64]$} \\
\hline \multicolumn{4}{|l|}{ Employment (no) } \\
\hline Yes & $\begin{array}{c}0.97 \\
{[0.79,1.19]}\end{array}$ & $\begin{array}{c}2.19^{* * *} \\
{[1.43,3.35]}\end{array}$ & $\begin{array}{c}1.06 \\
{[0.71,1.56]}\end{array}$ \\
\hline \multicolumn{4}{|l|}{ Residency status (other) } \\
\hline Canadian citizen & $\begin{array}{c}1.31^{* *} \\
{[1.11,1.55]}\end{array}$ & $\begin{array}{c}1.44^{*} \\
{[1.09,1.92]}\end{array}$ & $\begin{array}{c}1.13 \\
{[0.76,1.68]}\end{array}$ \\
\hline Landed immigrant or permanent resident & $\begin{array}{c}1.21 \\
{[0.99,1.48]}\end{array}$ & $\begin{array}{c}1.34 \\
{[0.95,1.90]}\end{array}$ & $\begin{array}{c}1.26 \\
{[0.79,2.01]}\end{array}$ \\
\hline \multicolumn{4}{|l|}{ Self-reported health (not good) } \\
\hline Good & $\begin{array}{c}1.33 \\
{[1.00,1.77]}\end{array}$ & $\begin{array}{c}1.58^{*} \\
{[1.09,2.30]}\end{array}$ & $\begin{array}{c}0.37 \\
{[0.08,1.70]}\end{array}$ \\
\hline \multicolumn{4}{|l|}{ No. of partners in last 12 months $(1-3)$} \\
\hline $4-5$ & $\begin{array}{c}1.27 \\
{[0.95,1.68]}\end{array}$ & $\begin{array}{c}1.18 \\
{[0.80,1.75]}\end{array}$ & $\begin{array}{c}1.20 \\
{[0.32,4.45]}\end{array}$ \\
\hline$>5$ & $\begin{array}{c}1.52^{* *} \\
{[1.14,2.02]}\end{array}$ & $\begin{array}{c}1.94^{* *} \\
{[1.26,2.97]}\end{array}$ & $\begin{array}{c}0.94 \\
{[0.27,3.30]}\end{array}$ \\
\hline \multicolumn{4}{|l|}{ Visited sexual health clinic (no) } \\
\hline Yes & $\begin{array}{c}1.78^{* * *} \\
{[1.30,2.44]}\end{array}$ & $\begin{array}{c}1.15 \\
{[0.65,2.00]}\end{array}$ & $\begin{array}{c}1.70 \\
{[0.48,6.01]}\end{array}$ \\
\hline \multicolumn{4}{|l|}{ Difficulty in getting sexual healthcare (no) } \\
\hline Yes & $\begin{array}{c}0.89 \\
{[0.55,1.43]}\end{array}$ & $\begin{array}{c}0.45^{*} \\
{[0.21,0.97]}\end{array}$ & $\begin{array}{c}1.24 \\
{[0.41,3.77]}\end{array}$ \\
\hline
\end{tabular}

N.B.: ${ }^{*}=$ significant at $p<0.05 .{ }^{* *}=$ significant at $p<0.01 .{ }^{* * *}=$ significant at $p<0.001$.

profile of the participants according to their knowledge, attitude, and use of condom. Logistic regression models were then performed to test the association between outcome and explanatory variables. Three different models were run for three outcome variables. Results of regression analyses were presented as odds ratios and $95 \%$ confidence intervals. Statistical significance was set at $p<0.05$. Level of multicollinearity among the variables used in regression analyses was assessed using variance 


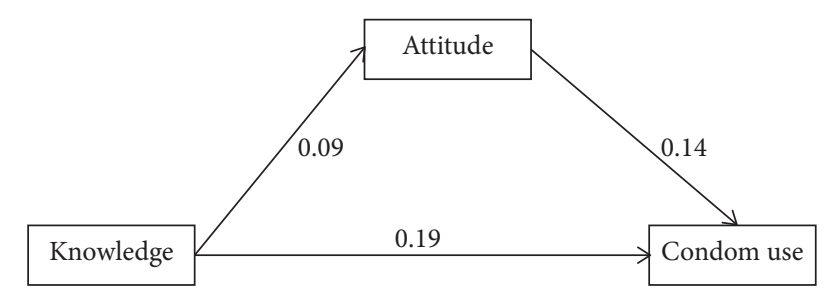

FIGURe 3: Path analysis showing association between knowledge and attitude towards condom use with its practice.

inflation factors (VIF). The VIF statistic for all three models was below 4 , while $<10$ was indicated the acceptable level of multicollinearity.

\section{Results}

As shown in Table 1, 22.30\% of the participants correctly responded that the condom is the best protection against HIV transmission, $31.77 \%$ of the men had positive attitude, and $62.43 \%$ reported using condom regularly during the last 12 months.

As shown in Figure 1, more than a quarter of the participants had neutral opinion towards comfort, appealingness, enjoyableness, pleasure-enhancing effect, willing to avoiding, and sign of concern and responsibility regarding condom use.

Figure 2 shows that the bulk of participants reported undetectable viral load as the main reason for not using condoms. Having no HIV/STIs in them and their partners were the next two most commonly reported reasons for not using condoms.

Results of regression analyses are presented in Table 2. Those in the lower age groups (e.g., 20-29 years) had relative higher odds of having correct knowledge of condom (odds ratio $=1.25,95 \% \mathrm{CI}=1.02,1.53$ ), positive attitude (odds ratio $=2.03,95 \% \mathrm{CI}=1.24,3.34$ ), and use of condom (odds ratio $=1.38,95 \% \mathrm{CI}=0.95,2.02$ ). Those who were currently married had more positive attitude towards condom use compared with their unmarried counterparts (odds ratio $=1.46,95 \% \mathrm{CI}=1.20,1.78)$. Ethnicity did not show any significant association with any of the three outcomes. Compared with those who had completed university education, those in the secondary education group had lower odds of good knowledge (odds ratio $=0.85,95 \% \mathrm{CI}=0.74$, 0.98 ), and those in the college/preuniversity group had lower odds of using condoms during the last 12 months (odds ratio $=0.30,95 \% \mathrm{CI}=0.10,0.94$ ). Having an employment also showed higher odds of having positive attitude towards condom use (odds ratio $=2.19,95 \% \mathrm{CI}=1.43,3.35$ ). $\mathrm{Re}-$ garding residency status, Canadian residents had higher odds of having correct knowledge of condom (odds ratio $=1.31,95 \% \mathrm{CI}=1.11,1.55)$ and positive attitude towards condom use (odds ratio $=1.44,95 \% \mathrm{CI}=1.09,1.92$ ). Those who reported being in good physical health had higher odds of having positive attitude towards condom use (odds ratio $=1.58,95 \% \mathrm{CI}=1.09,2.30$ ). Having more than 5 partners during the last 12 months also showed a positive association with having correct knowledge of condom (odds ratio $=1.52,95 \% \mathrm{CI}=1.14,2.02)$ and positive attitude towards condom use (odds ratio $=1.94,95 \% \mathrm{CI}=1.26,2.97$ ). Having visited sexual health clinics showed a positive association with having correct knowledge of condom (odds ratio $=1.78,95 \% \mathrm{CI}=1.30,2.44$ ), and having experienced difficulty in accessing sexual health showed a negative association towards condom use (odds ratio $=0.45,95 \%$ $\mathrm{CI}=0.21,0.97)$.

Figure 3 indicates a weak but positive association between condom knowledge and use $(b=0.19)$. There was also significant mediation of the association between condom knowledge and use by attitude towards condom use. Knowledge of condom use showed a mild correlation (0.14) with attitude and attitude with condom use (0.19).

\section{Discussion}

4.1. Main Findings. Based on quantitative data from the weSpeak study, this study aimed to explore the sociodemographic and healthcare-related factors that are associated with knowledge, attitude, and use of condom among African, Caribbean, and black men living in Ontario. Our findings indicate that more than three-quarters of the participants correctly responded that the condom is the best protection against HIV transmission, where less than onethird had positive attitude towards condom use and about two-thirds reported using condoms regularly during the last 12 months. Descriptive analysis also indicated that the bulk of participants reported undetectable viral load and having no HIV/STIs in them and their partners as the main reasons for not using condoms. Contextual data on the nonuse of condoms are critical for addressing the misconceptions and negative attitudes and thereby promoting its use among ACB men.

Among the sociodemographic factors, lower age groups, living with a spouse, having university-level education, Canadian residency, good subjective health, having $>5$ partners, and having visited sexual health clinics showed a positive association with the outcome variables. However, it is worthy of attention that participants' residency status was found to be an important factor that was contributing to correct knowledge of condom effectiveness in HIV prevention and positive attitude towards condom use. This implies that new comers and nonresidents could be more at risk for HIV and STI transmission, as they may not be up to date with regard to their understanding, their attitude, and condomless sex practice. Surprisingly, ethnic background did not show any significant association with any of the outcomes, signifying that the level of knowledge, attitude, and practice do not vary substantially among the ethnic groups. However, it is worthy of attention that participants' residency status was an important factor for having correct knowledge of condom and positive attitude towards condom use. This is perhaps because the nonresidents or new immigrants are less likely to avail or access the resources that can equip them with proper knowledge and attitude to avoid engaging in risky sexual behaviours [28-32]. As newcomers, especially from low-income settings, people generally face difficulties in getting acquainted with the healthcare system 
(such as getting health insurance) and making the first move to seeking care. Several factors can be responsible for that: health literacy, official language proficiency, and concept of health communication in a different culture [33-37]. This can be more prominent for sexual and reproductive health issues among men who tend to ignore such issues as temporary and something that will heal itself over time [22, 38-40]. Current sexual health programmes should therefore pay special attention to the individuals with permanent residency status. As expected, having higher education showed a positive association with good knowledge compared with those with the lowest educational level. However, there are no significant associations between education, attitude, and practice. Having an employment and good subjective health also showed higher odds of having positive attitude towards condom use, but not with knowledge and practice.

Interestingly, having more than 5 partners during the last 12 months also showed a positive association with having correct knowledge of condom and positive attitude towards condom use. It is likely that men having multiple relations or more experiences are more likely to peer-learn the correct information and grow protective attitude. At the same, it is important to bear in mind that having multiple partners itself is considered a risky behaviour and not a recommended way of gaining better knowledge and attitude towards condom use. Lastly, having visited sexual health clinics showed a positive association with having correct knowledge of condom, and having experienced difficulty in accessing sexual health showed a negative association towards condom use. Sexual health-seeking behaviour is an important factor for prevention and intervention of HIV and other STIs. Having access to sexual healthcare and careseeking behaviour are vital for meeting the health and reproductive needs especially among minority and marginalised communities. Results indicated that men who reported having difficulty in accessing care were less likely to have positive attitude towards condom use. This finding is understandable given the fact that an individual's experience and interaction with the healthcare system can greatly influence health-promoting attitude and behaviour. It is therefore recommended that healthcare policymakers take necessary measures to address the negative experiences and difficulties in accessing sexual healthcare among ACB men. Future studies should focus on more healthcare- and culture-related factors to investigate the level of knowledge, attitude, and practice of condom use among racial and marginalised population in Canada.

4.2. General Discussion. In Ontario, African, Caribbean, and black men account for almost $60 \%$ of the estimated number of HIV-positive people (through heterosexual contact), although they constitute less than $5 \%$ of the province's population. However, current HIV research, programming, and policies in Ontario are not aligned with heterosexual $\mathrm{ACB}$ men's needs and interests and fail to engage them in community responses to HIV. The weSpeak is a multisite (Ottawa, Toronto, London, and Windsor) project that is targeted to explore the sociocultural and sociopolitical conditions that contribute to HIV-related health disparities among ACB men; examine social and behavioural vulnerabilities to HIV among ACB men, including their social identities related to race, class, gender, and sexualities; generate, appraise, and share new knowledge; and support its translation into intervention and practice. Overall, this project is expected to strengthening multiple-sector partnerships and collaboration in HIV responses of $\mathrm{ACB}$ communities; identifying initiatives to strengthen resilience; building critical health literacy; supporting ACB men's involvement in community responses to HIV; building capacity in CBR and policy analysis; and generating new knowledge to reduce HIV-related health disparities in ACB communities to address the HIV epidemic in Ontario and beyond.

4.3. Strengths and Limitations of the Study. Findings of the present study highlight the factors associated with knowledge, attitude, and use of condom among ACB men in Ontario, which will contribute to a better understanding of the relevant factors influencing HIV vulnerability among heterosexual ACB men. It may also inform evidence-based policy making in the field. Although the sample population was relatively small, participants were selected cautiously, and the analysis was limited to only sexually active men who reported having a casual partner during the last 12 months. Another important strength was the inclusion of ACB men regarding of their residency status. As we included both Canadian citizens/permanent residents and study/permit holders, it helped get a better comparative picture of the factors that are associated with the outcome variables. We also used path analysis to assess the structural relationship knowledge, attitude, and practice of condom use. More importantly, we included men's medical visit for sexual health clinics in the last 12 months and experience of any difficulty in accessing care, which are good indicators of health-promoting behaviour and are likely to influence both the attitude and practice of condom use. There are some limitations to report as well. We used cross-sectional data for this analysis, which implies that the associations cannot be taken for casual relations. Condom use knowledge refers to the understanding that regular condom utilization is protective against HIV infection, rather than the knowledge of condom using manual. Last but not least, the sample size was not a representative of the general population, and therefore, the findings may not be applicable for the entire male population of Ontario.

\section{Conclusion}

This study was a part of the series of research projects embedded within the weSpeak programme of research. This study investigated the sociodemographic and healthcarerelated factors that are associated with knowledge, attitude, and use of condom among heterosexual ACB men in Ontario. In short, more than three-quarters of the participants responded that the condom is the best protection 
against HIV transmission, less than one-third had positive attitude towards condom use, and about two-thirds reported using condom regularly during the last 12 months. Several sociodemographic and healthcare-related factors were found to be significantly associated with the outcome variables, addressing which could result in better knowledge, attitude, and use of condom in the target population. Although the data were cross-sectional and population was not representative of the province, it is expected that the findings will enhance the current understanding of the potential risk factors of poor condom use and HIV-related knowledge and attitude among ACB men in Ontario. This will aid in designing evidence-based interventions and other initiatives to reduce heterosexual ACB men's vulnerability to HIV and its associated consequences.

\section{Data Availability}

Data can be made available upon request to the corresponding author.

\section{Ethical Approval}

The study was approved by the Ethical Review Board of Ryerson University (REB 2015-118).

\section{Consent}

All participants gave written consent prior to taking part in the interview.

\section{Conflicts of Interest}

The authors declare that they have no conflicts of interest.

\section{Acknowledgments}

The study was funded by Ontario HIV Treatment Network (OHTN), and the Canadian Institute of Health Research (CIHR).

\section{References}

[1] S. E. Collins, S. L. Clifasefi, J. Stanton et al., "Communitybased participatory research (CBPR): towards equitable involvement of community in psychology research," American Psychologist, vol. 73, no. 7, pp. 884-898, 2018.

[2] A. S. Ismael and J. M. S. Zangana, "Knowledge, attitudes and practice of condom use among males aged (15-49) years in erbil governorate," Global Journal of Health Science, vol. 4, pp. 27-36, 2012.

[3] E. Starbird, M. Norton, and R. Marcus, "Investing in family planning: key to achieving the sustainable development Goals," Global Health: Science and Practice, vol. 4, no. 2, pp. 191-210, 2016.

[4] S. A. Adedini, C. Odimegwu, E. N. Imasiku, and D. N. Ononokpono, "Unmet need for family planning: implication for under-five mortality in Nigeria," Journal of Health, Population, and Nutrition, vol. 33, no. 1, pp. 187-206, 2015.

[5] C. K. Ajaero, C. Odimegwu, I. D. Ajaero, and C. A. Nwachukwu, "Access to mass media messages, and use of family planning in Nigeria: a spatio-demographic analysis from the 2013 DHS," BMC Public Health, vol. 16, no. 1, 2016.

[6] S. Singh, G. Sedgh, and R. Hussain, "Unintended pregnancy: worldwide levels, trends, and outcomes," Studies in Family Planning, vol. 41, no. 4, pp. 241-250, 2010.

[7] D. Hubacher, I. Mavranezouli, and E. McGinn, "Unintended pregnancy in sub-Saharan Africa: magnitude of the problem and potential role of contraceptive implants to alleviate it," Contraception, vol. 78, no. 1, pp. 73-78, 2008.

[8] G. Bishwajit, S. Tang, S. Yaya, and Z. Feng, "Unmet need for contraception and its association with unintended pregnancy in Bangladesh," BMC Pregnancy and Childbirth, vol. 17, no. 1, 2017.

[9] L. Alkema, V. Kantorova, C. Menozzi, and A. Biddlecom, "National, regional, and global rates and trends in contraceptive prevalence and unmet need for family planning between 1990 and 2015: a systematic and comprehensive analysis," The Lancet, vol. 381, no. 9878, pp. 1642-1652, 2013.

[10] S. I. McCoy, R. Buzdugan, L. J. Ralph et al., "Unmet need for family planning, contraceptive failure, and unintended pregnancy among HIV-infected and HIV-uninfected women in Zimbabwe," PLoS One, vol. 9, no. 8, Article ID e105320, 2014.

[11] A. Nzokirishaka and I. Itua, "Determinants of unmet need for family planning among married women of reproductive age in Burundi: a cross-sectional study," Contraception and Reproductive Medicine, vol. 3, no. 1, 2018.

[12] M. J. Steiner and W. Cates, "Are condoms the answer to rising rates of non-HIV sexually transmitted infections? Yes," BMJ, vol. 336 , no. 7637 , p. $184,2008$.

[13] S. M. Hashemi-Shahri, B. Sharifi-Mood, H.-R. Kouhpayeh, J. Moazen, M. Farrokhian, and M. Salehi, "Sexually transmitted infections among hospitalized patients with human immunodeficiency virus infection and acquired immune deficiency syndrome (HIV/AIDS) in Zahedan, southeastern Iran," International Journal of High Risk Behaviors and Addiction, vol. 5, no. 3, 2016.

[14] S. O. Aral, M. Over, L. Manhart, and K. K. Holmes, "Sexually transmitted infections," in Disease Control Priorities in Developing Countries, D. T. Jamison, J. G. Breman, A. R. Measham et al., Eds., 2nd edition, World Bank, Washington, DC, USA, 2006, http://www.ncbi.nlm.nih.gov/ books/NBK11734/.

[15] G. M. Kassa, "Mother-to-child transmission of HIV infection and its associated factors in Ethiopia: a systematic review and meta-analysis," BMC Infectious Diseases, vol. 18, no. 1, 2018.

[16] National Academies Press, Factors Affecting Contraceptive Use in Sub-Saharan Africa, National Academies Press, Washington, DC, USA, 1993, https://www.ncbi.nlm.nih.gov/ books/NBK236407/.

[17] V. Mochache, A. Lakhani, H. El-Busaidy, M. Temmerman, and P. Gichangi, "Pattern and determinants of contraceptive usage among women of reproductive age from the Digo community residing in Kwale, Kenya: results from a cross-sectional household survey," BMC Women's Health, vol. 18, no. 1, 2018.

[18] S. R. Blackstone, U. Nwaozuru, and J. Iwelunmor, "Factors influencing contraceptive use in sub-saharan Africa: a systematic review," International Quarterly of Community Health Education, vol. 37, no. 2, pp. 79-91, 2017.

[19] A. O. Tsui, W. Brown, and Q. Li, "Contraceptive practice in sub-saharan africa," Population and Development Review, vol. 43, no. Suppl 1, pp. 166-191, 2017.

[20] A. F. Abraído-Lanza, A. N. Armbrister, K. R. Flórez, and A. N. Aguirre, "Toward a theory-driven model of 
acculturation in public health research," American Journal of Public Health, vol. 96, no. 8, pp. 1342-1346, 2006.

[21] M. Norredam, S. S. Nielsen, and A. Krasnik, "Migrants' utilization of somatic healthcare services in Europe-a systematic review," The European Journal of Public Health, vol. 20, no. 5, pp. 555-563, 2010.

[22] D. Rade, G. Crawford, R. Lobo, C. Gray, and G. Brown, "Sexual health help-seeking behavior among migrants from sub-saharan africa and south east asia living in high income countries: a systematic review," International Journal of Environmental Research and Public Health, vol. 15, no. 7, p. 1311, 2018.

[23] J. Rademakers, I. Mouthaan, and M. de Neef, "Diversity in sexual health: problems and dilemmas," The European Journal of Contraception \& Reproductive Health Care, vol. 10, no. 4, pp. 207-211, 2005.

[24] R. J. Kosgei, K. M. Lubano, C. Shen et al., "Impact of integrated family planning and HIV care services on contraceptive use and pregnancy outcomes: a retrospective cohort study," Journal of Acquired Immune Deficiency Syndromes, vol. 58, pp. e121-e126, 1999.

[25] I. Konkor, E. S. Lawson, R. Antabe et al., "An intersectional approach to HIV vulnerabilities and testing among heterosexual african caribbean and Black men in London, Ontario: results from the weSpeak study," Journal of Racial and Ethnic Health Disparities, vol. 7, no. 6, pp. 1140-1149, 2020.

[26] I. Konkor, R. Antabe, P. Mkandawire et al., "Knowledge of sexual partner's HIV serostatus and the practice of safer sex among heterosexual men of African descent in London, Ontario," Ethnicity \& Health, pp. 1-13, 2020.

[27] C. George, B. D. Adam, S. E. Read et al., "The MaBwana Black men's study: community and belonging in the lives of African, Caribbean and other Black gay men in Toronto," Culture, Health \& Sexuality, vol. 14, no. 5, pp. 549-562, 2012.

[28] A. Quesnel-Vallée, M. S. Setia, M. Abrahamowicz, P. Tousignant, and J. Lynch, "Access to health care in $\mathrm{Ca}$ nadian immigrants: a longitudinal study of the national population health survey," Health \& Social Care in the Community, vol. 19, pp. 70-79, 2011.

[29] P. Caulford and J. D'Andrade, "Health care for Canada's medically uninsured immigrants and refugees," Canadian Family Physician, vol. 58, pp. 725-727, 2012.

[30] B. D. Gushulak, K. Pottie, J. H. Roberts, S. Torres, and M. DesMeules, "Migration and health in Canada: health in the global village," Canadian Medical Association Journal, vol. 183, no. 12, pp. E952-E958, 2011.

[31] K. B. Newbold, "Health care use and the Canadian immigrant population," International Journal of Health Services, vol. 39, no. 3, pp. 545-565, 2009.

[32] F. G. De Maio and E. Kemp, "The deterioration of health status among immigrants to Canada," Global Public Health, vol. 5, no. 5, pp. 462-478, 2010.

[33] E. Ng, K. Pottie, and D. Spitzer, "Official language proficiency and self-reported health among immigrants to Canada," Health Reports, vol. 22, no. 4, pp. 15-23, 2011.

[34] K. Okrainec, G. L. Booth, S. Hollands, and C. M. Bell, "Language barriers among the foreign-born in Canada: agreement of self-reported measures and persistence over time," Journal of Immigrant and Minority Health, vol. 19, no. 1, pp. 50-56, 2017.

[35] E. Ngwakongnwi, B. R. Hemmelgarn, R. Musto, H. Quan, and K. M. King-Shier, "Experiences of French speaking immigrants and non-immigrants accessing health care services in a large Canadian city," International Journal of Environmental
Research and Public Health, vol. 9, no. 10, pp. 3755-3768, 2012.

[36] M. S. Zanchetta and I. M. Poureslami, "Health literacy within the reality of immigrants' culture and language," Canadian Journal of Public Health, vol. 97, no. S2, pp. S28-S33, 2006.

[37] L. Magalhaes, C. Carrasco, and D. Gastaldo, "Undocumented Migrants in Canada: a scope literature review on health, access to services, and working conditions," Journal of Immigrant and Minority Health, vol. 12, no. 1, pp. 132-151, 2010.

[38] M. Ruiz-Casares, J. Cleveland, Y. Oulhote, C. DunkleyHickin, and C. Rousseau, "Knowledge of healthcare coverage for refugee claimants: results from a survey of health service providers in montreal," PLoS One, vol. 11, Article ID e0146798, 2016.

[39] Y. T. Jahangir and S. B. Meyer, "Understanding access to and utilisation of sexual health services by south asian immigrant men in western countries: a scoping review," Journal of Immigrant and Minority Health, vol. 22, no. 3, pp. 621-633, 2020.

[40] "Recent im/migration to Canada linked to unmet health needs among sex workers in Vancouver, Canada: findings of a longitudinal study," 2020, https://europepmc.org/article/ pmc/pmc5496658. 